\title{
Simple HPLC-Fluorescence Determination of Raspberry Ketone in Fragrance Mist after Pre-Column Derivatization with 4-Hydrazino-7-nitro-2,1,3-benzoxadiazole
}

\author{
Yasuhiko Higashi \\ Department of Analytical Chemistry, Faculty of Pharmaceutical Sciences, Hokuriku University, Kanazawa, Japan \\ Email: y-higashi@hokuriku-u.ac.jp
}

Received 9 May 2016; accepted 20 June 2016; published 23 June 2016

Copyright (C) 2016 by author and Scientific Research Publishing Inc.

This work is licensed under the Creative Commons Attribution International License (CC BY).

http://creativecommons.org/licenses/by/4.0/

(c) (i) Open Access

\section{Abstract}

Raspberry ketone \{RK, 4-(4-hydroxyphenyl)butan-2-one\} is a natural compound contained in raspberry, and is added to cosmetics for skin whitening. It is very important to measure the RK level in cosmetics for quality assessment, since RK structurally resembles 4-(4-hydroxyphenyl)-2butanol, which causes leukoderma on consumers' skin. Here, we present a simple HPLC-fluorescence method for determination of RK in a fragrance mist by pre-column derivatization with 4-hydrazino-7-nitro-2,1,3-benzoxadiazole hydrazine (NBD-H), which reacts with the carbonyl group of RK. The NBD-RK derivative was eluted from a reversed-phase ODS column, and detected with excitation at $470 \mathrm{~nm}$ and emission at $550 \mathrm{~nm}$. The retention time of NBD-RK derivative obtained by reaction with $\mathrm{NBD}-\mathrm{H}$ at $80^{\circ} \mathrm{C}$ for $20 \mathrm{~min}$ was $10.3 \mathrm{~min}$. The standard curve was linear in the range of 0.2 to $10 \mu \mathrm{g} / \mathrm{mL}$, with a correlation coefficient $\left(r^{2}\right)$ value of 0.9980 . The lower limit of detection was $0.018 \mu \mathrm{g} / \mathrm{mL}$ (absolute amount of $1.8 \mathrm{pmol}$ ). The coefficients of variation were less than 8.1\%. The content of $\mathrm{RK}$ in fragrance mist $(1.00 \mathrm{~mL}$ ) was $1.18 \pm 0.07 \mathrm{mg}$ (range: 1.12 to 1.28 $\mathrm{mg}, n=5)$. Recovery tests were satisfactory $(83.9 \% \pm 3.9 \%$; range: 79.6 to $88.8 \%, n=5)$.

\section{Keywords}

Raspberry Ketone, High-Performance Liquid Chromatography, 4-Hydrazino-7-nitro-2,1,3-benzoxadiazole, Derivatization, Fluorescence

\section{Introduction}

Raspberry ketone \{RK, 4-(4-hydroxyphenyl)butan-2-one $\}$ is a natural phenolic compound present in red rasp-

How to cite this paper: Higashi, Y. (2016) Simple HPLC-Fluorescence Determination of Raspberry Ketone in Fragrance Mist after Pre-Column Derivatization with 4-Hydrazino-7-nitro-2,1,3-benzoxadiazole. Journal of Analytical Sciences, Methods and Instrumentation, 6, 44-49. http://dx.doi.org/10.4236/jasmi.2016.62006 
berry and is commonly added to foods such as yoghurts, juices, desserts and so on. It was reported to have an anti-obesity effect [1]-[3]. Also, depigmenting activity of RK was noted 4 to 5 weeks after application to C57 black mice, and the melanin content in the hair of the mice was decreased [4]. In cultivated murine B16 melanoma cells, RK inhibited melanogenesis through post-transcriptional regulation of tyrosinase gene expression [5]. It was recently reported to suppress proliferation of normal melanocytes [6]. These findings indicated that RK would be useful for skin whitening, and RK-added cosmetics are already commercially available. However, cosmetics containing rhododendrol \{4-(4-hydroxyphenyl)-2-butanol\}, which structurally resembles RK, were withdrawn from the market in July 2013, because leukoderma was observed on consumers' hands and face [7]. Thus, it is very important to measure the RK level in cosmetics for quality assessment, since RK may have potential to induce side effects like those of 4-(4-hydroxyphenyl)-2-butanol.

High-performance liquid chromatographic (HPLC) methods with ultraviolet-visible absorption detection have been developed to determine raspberry ketone in various raspberries and numerous food products [8] [9]. A simple gas chromatographic (GC) method using a flame ionization detector was established for the measurement of RK in insect bait concentrates [10]. Although a coupled loop-type HPLC-GC method was established for analysis of RK in raspberry sauce, this technique may be unsuitable for broad application [11]. In addition, GC and HPLC methods coupled with mass spectrometry have been utilized for RK determination, but the equipment is expensive and complex [12] [13].

RK possesses a phenolic hydroxyl group as well as a carbonyl group in the chemical structure. To improve selectivity and detection sensitivity, derivatization is expected to be effective. 4-Hydrazino-7-nitro-2,1,3-benzoxadiazole (NBD-H) has been used as a fluorescent labeling agent for carbonyl compounds for HPLC-fluorescence detection [14] [15]. Since the NBD moiety is characterized by excitation and emission wavelengths in the visible region, measurements should not be greatly affected by UV-absorbing compounds.

Therefore, in the present study, a simple and convenient HPLC-fluorescence method for determination of RK in fragrance mist after pre-column derivatization with NBD-H was established. The derivatization scheme is shown in Figure 1.

\section{Materials and Methods}

\subsection{Materials}

RK and NBD-H hydrazine were purchased from Tokyo Chemical Industry Co., Ltd. (Tokyo, Japan). Fragrance mist was obtained via the internet. Acetonitrile was purchased from Kanto Chemical Co., Inc. (Tokyo, Japan). Trifluoroacetic acid was obtained from Wako Pure Chemical Industries (Osaka, Japan).

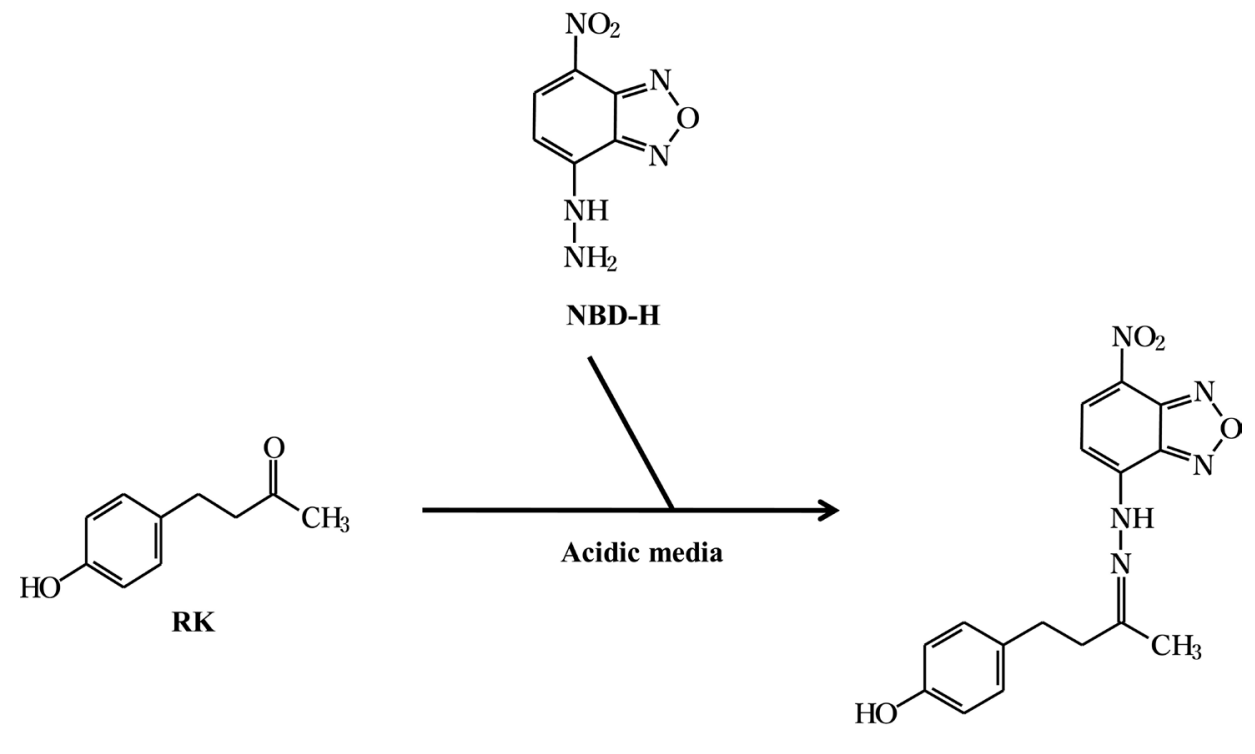

NBD-RK 


\subsection{Chromatographic System}

The HPLC system consisted of a model L-2130 pump (Hitachi, Tokyo, Japan), a Rheodyne injection valve (Cotati, CA, U.S.A.) with a 50- $\mu \mathrm{L}$ loop, and a model F-1050 fluorescence spectrophotometer(Hitachi) with excitation at $470 \mathrm{~nm}$ and emission at $550 \mathrm{~nm}$. A $150 \mathrm{~mm} \times 4.6 \mathrm{~mm}$ i.d. HPLC column $\left(\mathrm{C}_{18}\right.$-MS-II, Nacalai Tesque, Kyoto, Japan) containing $5 \mu \mathrm{m}$ particles of $\mathrm{C}_{18}$ packing material was used. Peak quantification was performed using a model D-2500 Chromato-Integrator (Hitachi). The mobile phase was prepared by the addition of acetonitrile $(460 \mathrm{~mL})$ to $540 \mathrm{~mL}$ of Milli-Q water containing trifluoroacetic acid $(0.1 \% \mathrm{v} / \mathrm{v})$. Samples were eluted from the column at room temperature at a flow rate of $1.0 \mathrm{~mL} / \mathrm{min}$.

\subsection{Preparation of Standard Solutions}

Ultrapure water was obtained from a Milli-Q water purification system (Simplicity ${ }^{\circledR}$ UV, Millipore Corporation, Bedford, MA, USA). Standard solution was prepared by dissolving RK $(50 \mathrm{mg})$ in acetonitrile $(200 \mathrm{~mL})$ and stored at $4^{\circ} \mathrm{C}$. Working standard solutions $(0.2,0.5,1,2,5$ and $10 \mu \mathrm{g} / \mathrm{mL})$ were prepared by dilution with acetonitrile.

\subsection{Derivatization}

A previous method using NBD-H required $1 \mathrm{~h}$ reaction time at room temperature in trifluoroacetic acid solution $(0.0025 \mathrm{v} / \mathrm{v} \%)$ in acetonitrile for derivatization [15]. This method was used herewith minor modifications. Briefly, trifluoroacetic acid solution in acetonitrile $(0.0075 \mathrm{v} / \mathrm{v} \%, 100 \mu \mathrm{L})$ was added to diluted standard sample $(100 \mu \mathrm{L})$, and then NBD-H hydrazine solution in acetonitrile $(2 \mathrm{mg} / \mathrm{mL}, 100 \mu \mathrm{L})$ was added in a stoppered test tube(the final concentration of trifluoroacetic acid is the same as in the reported method [15]), and the mixture was vortexed. The top of the test tube was covered using a paper (PROWIPE, DAIO Paper Corp., Tokyo) wetted with ice-cold water, and then reaction at $80^{\circ} \mathrm{C}$ was performed in a water bath. The test tube was placed on ice for $2 \mathrm{~min}$. An aliquot ( $50 \mu \mathrm{L}$ ) was injected into the HPLC system.

\subsection{Application to Fragrance Mist Sample}

Fragrance mist (200 $\mu \mathrm{L}$ ) was dissolved in acetontrile $(200 \mathrm{~mL})$. The solution was diluted 1000 -fold, and then analyzed as described above.

\subsection{Evaluation of Recovery}

Fragrance mist $(200 \mu \mathrm{L})$ was spiked with $0.25 \mathrm{mg}$ of RK and diluted as described above (Application to fragrance mist sample). The resulting sample was analyzed to determine recovery of the added standard in order to assess the accuracy of the method.

$$
\text { Recovery value, } \%=100 \times \frac{(\text { Total amount after spiking })-(\text { Spiked amount })}{\text { (Original amount })}
$$

\section{Results and Discussion}

\subsection{Time Course of Derivatization of RK with NBD-H}

For the time course study, the reaction time was set at $10,20,30$ or 40 min at $80^{\circ} \mathrm{C}$. RK standard solution (1 $\mu \mathrm{g} / \mathrm{mL}, 100 \mu \mathrm{L})$, trifluoroacetic acid solution $(0.0075 \mathrm{v} / \mathrm{v} \%, 100 \mu \mathrm{L})$ and NBD-Hhydrazine $(2 \mathrm{mg} / \mathrm{mL}, 100 \mu \mathrm{L})$ were mixed appropriately and analysis was carried outas described in Materials and Methods. The peak area of NBD-RK reached maximum at 20 min (Figure 2). In a preliminary study, the peak area of NBD-RK at a reaction time of $20 \mathrm{~min}$ at $80^{\circ} \mathrm{C}$ was higher than those at 60 and $70^{\circ} \mathrm{C}$. Thus, we selected $20 \mathrm{~min}$ at $80^{\circ} \mathrm{C}$ as standard conditions.

\subsection{Chromatogram}

Figure 3 shows typical chromatograms obtained from (a) standard sample $(5 \mu \mathrm{g} / \mathrm{mL})$ and (b) test sample of a fragrance mist $(1 \mu \mathrm{L} / \mathrm{mL})$. The retention time of NBD-RK derivative was 10.3 min. A peak of NBD-RK derivative was observed in the test sample. The running time was set at $18 \mathrm{~min}$. 


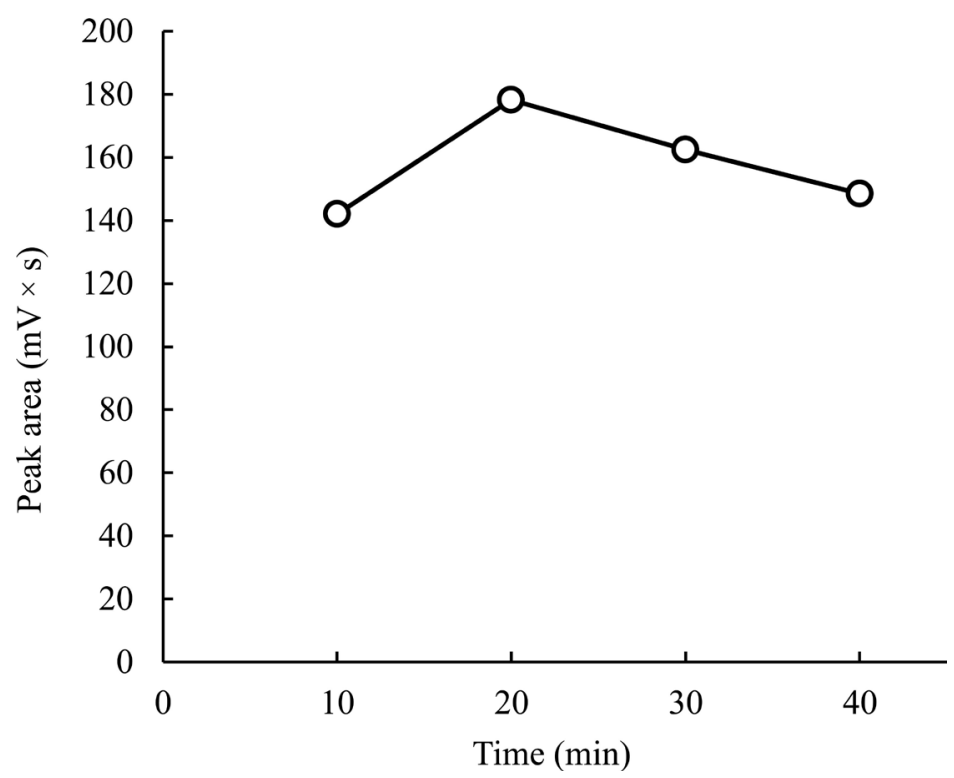

Figure 2. Plot of peak area versus reaction time for formation of the RK derivative with NBD-H. Data are mean values of two experiments.

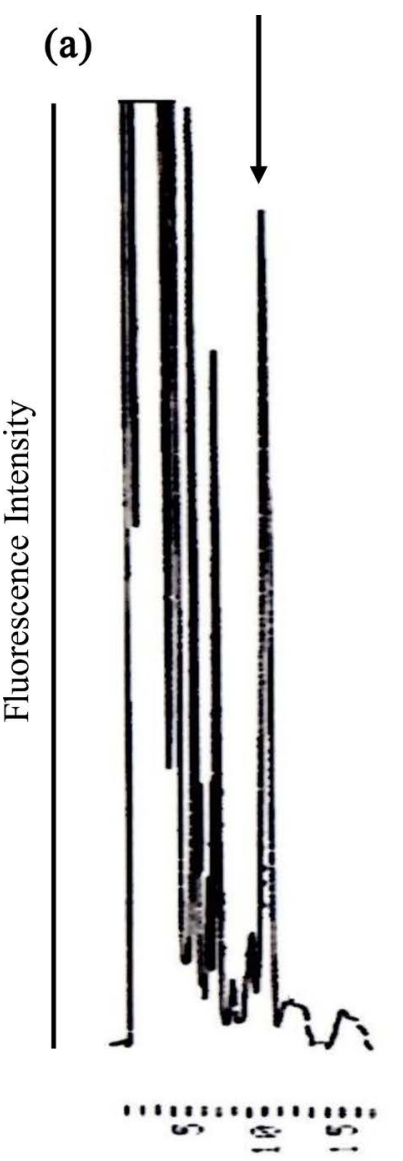

Time (min) (b)

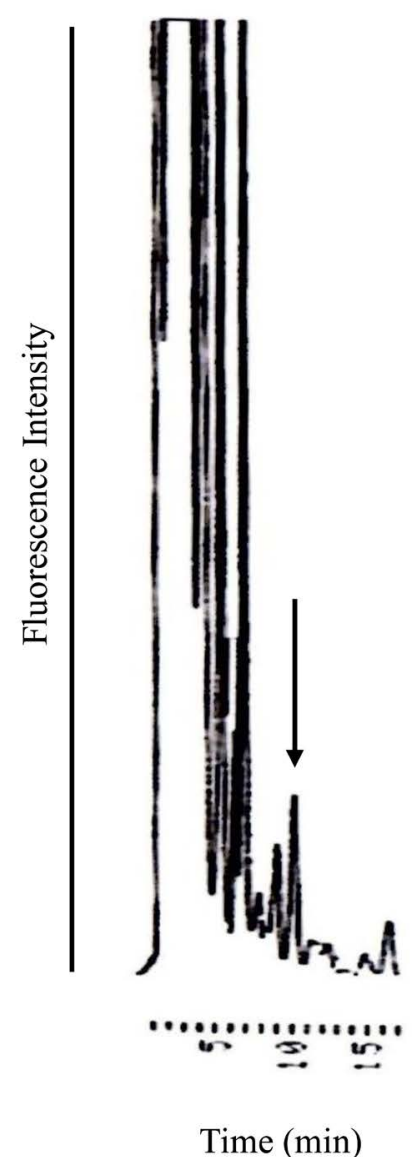

Figure 3. Typical chromatograms obtained for (a) standard $(5 \mu \mathrm{g} / \mathrm{mL})$ and (b) test sample of a fragrance mist ( $5 \mu \mathrm{L} / \mathrm{mL}$ ). Retention time of NBD-RK derivative (arrowed peak): $10.3 \mathrm{~min}$. 
Table 1. Intra- and inter-day assay reproducibility for determination of RK.

\begin{tabular}{cccc}
\hline RK $(\boldsymbol{\mu g} / \mathbf{m L})$ & Measured $(\boldsymbol{\mu g} / \mathbf{m L}$, mean \pm S.D., $\boldsymbol{n}=\mathbf{5})$ & C.V. $(\%)$ & Recovery $(\%)$ \\
\hline Intra-day assay & & & \\
\hline 0.2 & $0.192 \pm 0.011$ & 5.7 & 96.0 \\
1 & $0.982 \pm 0.033$ & 3.4 & 98.2 \\
10 & $10.2 \pm 0.3$ & 2.9 & 102.0 \\
Inter-day assay & & & 93.0 \\
10.2 & $0.186 \pm 0.015$ & 8.1 & 98.7 \\
10 & $0.987 \pm 0.045$ & 4.6 & 104.0 \\
\hline
\end{tabular}

Table 2. Level of RK in the mist sample and relative recovery.

\begin{tabular}{ccc}
\hline Day & RK level $(\mathrm{mg} / \mathrm{mL})$ & Recovery added $(0.25 \mathrm{mg})$ \\
Day 1 & 1.12 & 82.9 \\
Day 2 & 1.13 & 71.2 \\
Day 3 & 1.16 & 79.6 \\
Day 4 & 1.22 & 88.8 \\
Day 5 & 1.28 & 86.9 \\
Average \pm S.D.(R.S.D.) & $1.18 \pm 0.07(7.4 \%, n=5)$ & $83.9 \% \pm 3.9 \%(4.6 \%, n=5)$ \\
\hline
\end{tabular}

\subsection{Standard Curve of RK}

The standard curve of RK was constructed by plotting integrated peak area vs. concentration. The calibration plot was linear (slope, 317.4; intercept, -130.4 ) in the range of 0.2 to $10 \mu \mathrm{g} / \mathrm{mL}$ with a correlation coefficient $\left(r^{2}\right)$ value of 0.9980 . The lower limit of detection for RK was estimated as the concentration giving a detectable peak (signal-to-noise ratio of 3 or more), since the peak was located close to a medium blank peak at $9.1 \mathrm{~min}$. The value of the lower limit of detection was $0.018 \mu \mathrm{g} / \mathrm{mL}$ (absolute amount of $1.8 \mathrm{pmol}, 0.3 \mathrm{ng}$ ).

RK is a volatile compound, and has been analyzed by GC-mass spectrometry [10] and GC with a flame ionization detector [11], but those reports did not clearly describe the sensitivity of their methods. Also, the lower limit of detection of RK with the previous HPLC methods was not established [8] [9] [13]. However, HPLC analysis of carbonyl compounds (benzaldehyde, propionaldehyde and heptan-4-one) using NBD-H showed detection limits of $1.9 \mathrm{pmol}, 35 \mathrm{fmol}$ and $0.67 \mathrm{pmol}$, respectively [14] [15]. Therefore the sensitivity of the present method (1.8 pmol RK) appears to be sufficient for the purpose.

\subsection{Precision and Accuracy}

Precision and accuracy in intra-day and inter-day assays of RK are shown in Table 1. In the intra-day assay, the range of standard deviation was within $2.9 \%$ to $5.7 \%$ of the mean and recovery was within the range of $96.0 \%$ to $102.0 \%$. In the inter-day assay, the range of standard deviation was within $4.6 \%$ to $8.1 \%$ of the mean and recovery was within the range of $93.0 \%$ to $104.0 \%$.

\subsection{Analysis of a Fragrance Mist}

The developed method was used to determine RK in fragrance mist and in fragrance mist spiked with authentic standard. As shown in Table 2, the concentration of RK in fragrance mist was $1.18 \pm 0.07 \mathrm{mg} / \mathrm{mL}$ (average \pm S.D., range, 1.12 to $1.28 \mathrm{mg} / \mathrm{mL}, n=5$ ). Recovery of RK from spiked fragrance mist was $83.9 \% \pm 3.9 \%$ (average \pm S.D., range, $79.6 \%$ to $88.8 \%, n=5$ ).

\section{Conclusion}

A simple HPLC-fluorescence method for determination of RK in fragrance mist has been developed by using NBD-H as a fluorescence-labeling reagent. The accuracy, reproducibility and sensitivity of the method were satisfactory. The mean content of RK in the mist $(1.00 \mathrm{~mL})$ was found to be $1.18 \pm 0.07 \mathrm{mg}$. This system should be suitable for routine quality assessment of fragrance mist and should be readily adaptable for measurement of RK levels in other cosmetics or foods. 


\section{References}

[1] Morimoto, C., Satoh, Y, Hara, M., Inoue, S., Tsujita, T. and Okuda, H. (2005) Anti-Obese Action of Raspberry Ketone. Life Sciences, 77, 194-204. http://dx.doi.org/10.1016/j.lfs.2004.12.029

[2] Wang, L., Meng, X. and Zhang, F. (2012) Raspberry Ketone Protects Rats Fed High-fat Diets against Nonalcoholic Steatohepatitis. Journal of Medicinal Food, 15, 495-503. http://dx.doi.org/10.1089/jmf.2011.1717

[3] Park, K.S. (2015) Raspberry Ketone, a Naturally Occurring Phenolic Compound, Inhibits Adipogenic and Lipogenic Gene Expression in 3T3-L1 Adipocytes. Pharmaceutical Biology, 53, 870-875. http://dx.doi.org/10.3109/13880209.2014.946059

[4] Fukuda, Y., Nagano, M., Arimatsu, Y. and Futatsuka, M. (1998) An Experimental Study on Depigmenting Activity of 4-(p-Hydroxyphenyl)-2-butanone in C57 Black Mice. Journal of Occupational Health, 40, 97-102. http://dx.doi.org/10.1539/joh.40.97

[5] Victor Lin, C.H., Ding, H.Y., Kuo, S.Y., Chin, L.W., Wu, J.Y. and Chang, T.S. (2011) Evaluation of in Vitro and in Vivo Depigmenting Activity of Raspberry Ketone from Rheum officinale. International Journal of Molecular Sciences, 12, 4819-4835. http://dx.doi.org/10.3390/ijms12084819

[6] Kim, M., Baek, H.S., Lee, M., Park, H., Shin, S.S., Choi, D.W. and Lim, K.M. (2016) Rhododenol and Raspberry Ketone Impair the Normal Proliferation of Melanocytes through Reactive Oxygen Species-Dependent Activation of GADD45. Toxicology in Vitro, 32, 339-346. http://dx.doi.org/10.1016/j.tiv.2016.02.003

[7] Aoyama, Y., Ito, A., Suzuki, K., Suzuki, T., Tanemura, A., Nishigori, C., Ito, M., Katayama, I., Sugiura, S. and Matsunaga, K. (2014) The First Epidemiological Report of Rhododenol-Induced Leukoderma in Japan Based on a Nationwide Survey. The Japanese Journal of Dermatology, 124, 2095-2109.

[8] Fogy, I., Grundmann, H., Schmid, E.R., Huber, J.F.K. and Holzer, H. (1981) High-Pressure Liquid Chromatographic Determination of Raspberry Ketone in Natural and Artificially Aromatized Raspberry Products. Deutsche Lebensmittel-Rundschau, 77, 271-275.

[9] Borejsza-Wysocki, W., Goers, S.K., McArdle, R.N. and Hrazdina, G. (1992) (p-Hydroxyphenyl)butan-2-One Levels in Raspberries Determined by Chromatographic and Organoleptic Methods. Journal of Agricultural and Food Chemistry, 40, 1176-1177. http://dx.doi.org/10.1021/jf00019a018

[10] Perez, R.L. (1983) Gas Chromatographic Determination of Raspberry Ketone and Malathion in Insect Bait Concentrates. Journal of Chromatography A, 259, 176-180. http://dx.doi.org/10.1016/S0021-9673(01)87993-0

[11] Grob Jr. K. and Stoll, J.M. (1986) Loop-Type Interface for Concurrent Solvent Evaporation in Coupled HPLC-GC. Analysis of Raspberry Ketone in a Raspberry Sauce as an Example. Journal of High Resolution Chromatography, 9, 518-523. http://dx.doi.org/10.1002/jhrc.1240090906

[12] Beekwilder J., van der Meer I.M., Sibbesen, O., Broekgaarden, M., Qvist, I., Joern D. Mikkelsen, J.D. and Hall, R.D. (2007) Microbial Production of Natural Raspberry Ketone. Biotechnology Journal, 2, 1270-1279. http://dx.doi.org/10.1002/biot.200700076

[13] Lili, W., Yansong, W., Yan, Z., Xianjun, M., Lei, Y. and Fengqing, Z. (2011) Determination of Raspberry Ketone in Raspberry by High-Performance Liquid Chromatography Tandem Mass Spectrometry. 2011 International Conference on Human Health and Biomedical Engineering (HHBE), Jilin, 19-22 August 2011, 62-65. http://dx.doi.org/10.1109/hhbe.2011.6027897

[14] Gübitz, G., Wintersteiger, R. and Frei, R.W. (1984) Fluorogenic Labelling of Carbonyl Compounds with 7-Hydrazine4-nitrobenzo-2-oxa-1,3-diazole (NBD-H). Journal of Liquid Chromatography, 7, 839-854. http://dx.doi.org/10.1080/01483918408074006

[15] Uzu, S., Kanda, S., Imai, K., Nakashima, K. and Akiyama S. (1990) Fluorogenic Reagents: 4-Aminosulphonyl-7-hydrazino-2,1,3-benzoxadiazole, 4-(N,N-Dimethylaminosulphonyl)-7-hydrazino-2,1,3-benzoxadiazole and 4-Hydrazino7-nitro-2,1,3-benzoxadiazole Hydrazine for Aldehydes and Ketones. Analyst, 115, 1477-1482. http://dx.doi.org/10.1039/an9901501477 